\title{
Otolith Biomineralisation: Insights From a Microstructural and Microanalytical Study
}

\author{
A.McFadden ${ }^{1,2}$, B. Gillanders ${ }^{3}$, A. Pring ${ }^{1,4}$ and B. Wade $^{2}$ \\ ${ }^{1}$ School of Chemistry and Physics, The University of Adelaide, Adelaide, Australia \\ ${ }^{2}$ Adelaide Microscopy, The University of Adelaide, Adelaide, Australia \\ ${ }^{3}$ School of Earth and Environmental Sciences, The University of Adelaide, Adelaide, Australia \\ ${ }^{4}$ Department of Mineralogy, The South Australian Museum, Adelaide, Australia
}

In conjunction with microstructural interpretation, variation of the $\mathrm{Sr} / \mathrm{Ca}$ ratio in otoliths of Platycephalus bassensis have been determined in an effort to uncover the role of biomineralisation in otolith trace element uptake. After subsequent microstructural analysis by Electron Backscatter Diffraction (EBSD), Sr/Ca ratios across otolith growth rings were determined by Electron Probe Microanalysis (EPMA). Results point towards heterogeneous $\mathrm{Sr} / \mathrm{Ca}$ ratios across an individual otolith, with ratio variation shown to be associated with changing crystal fabric. The apparent correlation between otolith microstructure and chemistry, indicates that $\mathrm{Sr}$ incorporation is not exclusively environmentally regulated as previously thought [1-3], but rather falls under the influence of both biological and environmental factors.

An otolith is a calcified structure essential to the inner ear of teleost fish, and enables the perception of both gravity and sound. Composed of $\mathrm{CaCO} 3$ in the form of aragonite, otoliths grow incrementally following a circadian rhythm, which falls under both physiological and environmental regulation [4-6]. Incorporated into the growing otolith structure are trace elements present in the environment which are used as a biological archive, allowing for the reconstruction of migration pathways, stock identification, age validations and elucidation of environmental histories [1]. Despite numerous life history reconstructions, accurate interpretation of otolith data remains hindered by the physiological regulation of many trace elements, and by extension the otolith biomineralisation process as a whole $[1,7]$.

Elements such as $\mathrm{Sr}$ which are thought to be environmentally regulated, are of particular interest in the reconstruction of environmental conditions such as temperature histories. However, comparisons of otolith and environmental $\mathrm{Sr} / \mathrm{Ca}$ ratios have produced reports of positive correlations [7, 8], negative correlations [3, 9], and some conclude no correlation at all [10]. Postulated explanations for the variance in correlation have been put down to inter-species differences, metabolic effects, and the existence of a correlative relationship exclusively at low temperatures [3, 10, 11]. Changes in $\mathrm{Sr} / \mathrm{Ca}$ ratio have been observed following a metamorphosis check in eel otoliths, with similar changes observed in the annual growth checks in bivalve shells [11-13]. These observations support the existence of a relationship between trace element concentrations (in particular $\mathrm{Sr}$ concentrations), and the microstructure of the otolith.

Resin embedded otoliths taken from wild-caught Platycephalus bassensis of Investigator Strait, South Australia were sectioned trans-axially to reveal the growth rings. Sections were subsequently mechanically polished to achieve a surface suitable for the collection of EBSD data. EBSD patterns were acquired on a Phillips XL30 FEG SEM equipped with an Oxford Instruments Channel 5 Nordlys EBSD detector. Operating conditions include an accelerating voltage of $15 \mathrm{kV}$ for EBSD mapping, at a tilt angle of $70^{\circ}$ and a working distance of $20 \mathrm{~mm}$. EPMA data was acquired on a CAMECA SXFive microprobe equipped with five wavelength dispersive spectrometers, and data processed on the Probe for EPMA ${ }^{\mathrm{TM}}$ software. Spot analyses were acquired at an accelerating voltage of $15 \mathrm{kV}$ and a beam current of $20 \mathrm{nA}$, with spot sizes ranging between a focussed beam and $20 \mu \mathrm{m}$. Maps were collected at $15 \mathrm{kV} / 100 \mathrm{nA}$, using a focussed beam, step size of $2 \mu \mathrm{m}$ and pixel dwell time of $100 \mathrm{msec}$. 
We present here the results of a microstructural and microanalytical study of fish otoliths, in the determination of $\mathrm{Sr} / \mathrm{Ca}$ ratio variation and its association with crystal fabric. Sr/Ca values as determined by EPMA, are shown to be heterogeneously distributed across the otolith growth rings (Fig 2a). SEM images and EBSD orientation data reveal the changes in otolith grain structure are associated with the changing $\mathrm{Sr} / \mathrm{Ca}$ values. The correlation between $\mathrm{Sr} / \mathrm{Ca}$ ratio and grain size (Fig 2b), is indicative that $\mathrm{Sr}$ is not completely regulated by the environment, but is instead controlled by a complex interaction of biological and kinetic effects [14].

[1] Campana, S.E., 1999, Marine Ecology Progress Series. 188: p. 263-297.

[2] Radtke, R.L., et al., 1996, Marine Biology. 127(1): p. 161-170.

[3] Townsend, D.W., et al., 1992, Journal of Experimental Marine Biology and Ecology. 160(1): p.131-140.

[4] Carlstrom, D.D., 1963, Biological Bulletin. 125(3): p. 441-\&.

[5] Degens, E.T., W.G. Deuser, and R.L. Haedrich, 1969, Marine Biology. 2(2): p. 105-\&.

[6] Pannella, G., 1971, Science. 173(4002): p. 1124-\&.

[7] Kalish, J.M., 1989, Journal of Experimental Marine Biology and Ecology. 132(3): p. 151-178.

[8] Limburg and K. E., 1995, Marine Ecology Progress Series. 119: p. 25-35.

[9] Radtke, R., et al., 1990, Environmental Biology of Fishes. 27(1): p. 51-61.

[10] Tzeng, W.N., J.C. Shiao, and Y. Iizuka, 2002, Marine Ecology Progress Series. 245: p. 213-221.

[11] Otake, T., 1994, MARINE ECOLOGY PROGRESS SERIES. 112: p. 189-193.

[12] Foster, L.C., et al., 2009, Geochemistry, Geophysics, Geosystems. 10(3): p. Q03003.

[13] Schöne, B.R., et al., 2013, Palaeogeography, Palaeoclimatology, Palaeoecology. 373(0): p. 50-59.

[14] The authors would like to acknowledge the support of the Adelaide Microscopy staff and the AMMRF, as well as Chris Izzo for his contribution of samples.
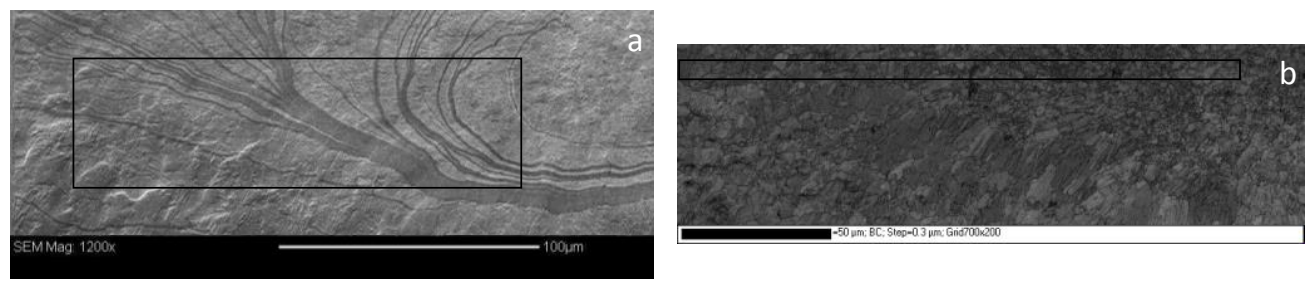

Figure 1: a) SEM Backscattered Electron (BSE) image of an otolith section, showing the organic rich rings as dark layers, and the otolith microstructure. Outlined box indicates the area of EBSD map . b) EBSD band contrast map displaying the otolith grain structure. Boxed area represents the region analysed for $\mathrm{Sr} / \mathrm{Ca}$ and grain diameter shown in Fig. 2.
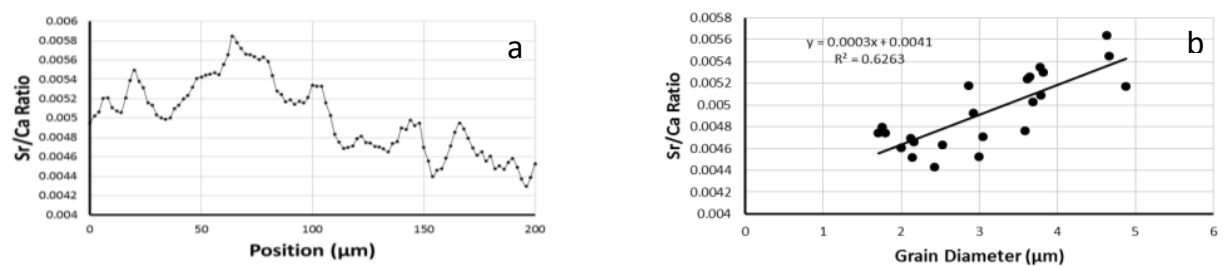

Figure 2: a) $\mathrm{Sr} / \mathrm{Ca}$ ratio variation as determined by EPMA spot analysis across the otolith structure, and b) The relationship between $\mathrm{Sr} / \mathrm{Ca}$ ratio and grain diameter $(\mu \mathrm{m})$ as determined from EBSD band contrast maps. 